\title{
Comparative Study by Simulation of Interlocking and Ordinary Building Blocks under Static Loads
}

\author{
Joseph Bikoun Mousi' ${ }^{1}$, Edmond Adjovi ${ }^{2}$ \\ ${ }^{1}$ Mechanics, Materials, Structures and Productivity Laboratory (LM'SP), Doctoral Training Unit in Physics and Engineering \\ Sciences, University of Douala, Douala, Cameroon \\ ${ }^{2}$ Laboratory of Energetics and Applied Mechanics (LEMA) of Polytechnic School of Abomey-Calavi, University of \\ Abomey-Calavi, Abomey-Calavi, Benin \\ Email: josephbikoun@gmail.com, adjed2012@gmail.com
}

How to cite this paper: Mousi, J.B. and Adjovi, E. (2020) Comparative Study by Simulation of Interlocking and Ordinary Building Blocks under Static Loads. Engineering, 12, 356-381. https://doi.org/10.4236/eng.2020.126028

Received: March 3, 2020

Accepted: June 21, 2020

Published: June 24, 2020

Copyright $\odot 2020$ by author(s) and Scientific Research Publishing Inc. This work is licensed under the Creative Commons Attribution International License (CC BY 4.0).

http://creativecommons.org/licenses/by/4.0/

(c) (i) Open Access

\begin{abstract}
In order to recommend the use of the masonry of chipboards with eviscerated bed joints and hollow vertical joints, we did a comparative study using simulation of the behavior of walls with traditional blocs and those of the new model of blocs. Thus, using Solidworks, we built up walls of $2.40 \mathrm{~m}$ length and $1.30 \mathrm{~m}$ height following strictly the real constraints of elevation. Using finite elements method, the meshing, loading and the observation of the behavior are done through CosmosWorks. We can define a study used by Solidworks and Cosmos Works interface, and introduce parameters of walls; the meshing is then done (here we have volumic elements with three noses); then the big rigidity matrix is defined; the equations are also defined and solved and results are presented in numerical and graphical form. Since that form of results is not easy to analyse, we passed them to MATLAB in order to have usual curves more easily to analyse. The difficulty here is based on the conception of geometry of piece which must have same constraints and dimensions corresponding exactly to the real model. The other difficulty is to define parameters to use for a heterogeneous material like masonry. Once those difficulties are solved, the logical follows fully the steps of finite elements method until the solution in terms of noses repartition constraints, displacements and deformations. Then, we simulated the behavior on vertical static load, vertical static load and horizontal applied load and composed loads (vertical and horizontal) which are real conditions generally known in masonry walls. It has been shown that the new kind of masonry has a better behavior than the traditional one when loaded in its plan; in contrary, the behavior is less when loaded in the perpendicular plan.
\end{abstract}




\section{Keywords}

Walls, Chipboards, Simulation, Behavior, Static, Finite Elements

\section{Introduction}

The serious economic crisis known in black African countries between the end of the years 80 and the beginning of the years 2000, has reduced the revenues of citizens [1]. In the same period, the costs of construction materials like cement, iron, wood, gravel and sand have increased quickly. This situation is a big handicap for social constructions for example. Otherwise, traditional constructions using chipboards, concrete and woods present some misturbings for the environment and sustainable development. Thus, it has become very important to have new materials which must permit the reduction of the constructions costs, ensure sustainable development and limit the effects on environment.

Thus, we made up the masonry of chipboards with eviscerated bed joints and hollow vertical joints which offer about 20\% (for masonry, and 14\% for concrete) of reduction of the costs and eliminate the use of wood for coffering and then, the impact on environment [2] [3]. But even the model is economically validated, we cannot recommend it since the mechanic behaviour remains unknown. For this reason, we did a basic comparative study based on current essays on the elements [4]. That one showed us that the behavior of the elements is the same like that for traditional masonry, since the main components are the same.

Since that technologic innovation concerns both the form of blocks and the implementation, the behavior must be studied in simulation of walls in the real conditions of use.

In France, the Batiment Technical and Scientific Center (CSTB) did very important studies in order to modelise the mechanic behavior of masonry when submitting on statics and dynamics loads [5] [6]. Today, valuable results are available on:

- Walls with mortar bed joints and vertical fill and nonfill joints, with coffered chainings, on static and dynamic loading;

- Walls with mortar bed joints and vertical fill and nonfill joints, with blocks chainings, on static and dynamic loading;

- Walls with glued bed joints and vertical nonfill joints, with blocks chainings, on static and dynamic loading.

Those studies realize a complete roundup of the behavior of masonry. But, the other which interests us, even it can be ranged in the second group studied by the CSTB, presents particularities (eviscerated bed joints, differentiation of odd and even beds, types of interlocking...), and that, we think, must induce differences on the level of mechanic behavior. It is then necessary to show the influence of those particularities on the behavior of the whole wall. 
In that study, we did a comparative study of traditional masonry and new model masonry in a real format. The mechanic behavior is observed and compared for the two types of masonries when submitted on static loads (vertical loads, vertical and horizontal loads, vertical and applied horizontal load).

In fact, as the security of human beings is concerned, we have to show that the new masonries have, in less, the same behavior than the traditional ones. If not, we must propose the conditions of use in order to have a new model which is economically and mechanically correct.

For that purpose, we first have a short presentation of the new masonries, after that, we present the method of simulation used, the results and their interpretation and the conclusion and perspectives of the study.

\section{Presentation of the Masonry of Chipboards with Eviscerated Bed Joints and Hollow Vertical Joints}

\subsection{Introduction}

The reader can have in the literature [7], a complete and right presentation of this model of masonry which constitutes the main object of our study. Here, we just have a short presentation of walls and elements in order to help the reader to have the difference between traditional masonries and the interest of the study.

\subsection{Conception of Parements}

The parement of one panel of standing wall of $2.4 \mathrm{~m}$ high for example is formed by five systems of two seats put up ones on others, through bed joints of $20 \mathrm{~mm}$ of thickness. Those two different seats are constituted by current chipboards (Figures 1(a)-(d)), coffering chipboards for vertical chaining (Figures 1(e)-(j)). They are closed at $2.2 \mathrm{~m}$ high by one seat composed of horizontals chaining coffering chipboards (Figure 1(k) and Figure 1(1)). Coffering chipboards of L, U, $\mathrm{U}$-ebrased and current are respectively intended to the integration of angles chainings of walls L, T or crossed, of free-running chainings, at the verticals and horizontals connecting chainings to outgoing angle, at intermediate vertical chainings.

By inspiring us of French equipment of masonries walls of compressed ground blocks, it is clear that the first set is constituted of a linking of chipboards of an entire length of $40 \mathrm{~cm}$, when the second one is constituted by mi-length $(20 \mathrm{~cm}$ ) chipboards (Figure 2 and Figure 3 ).

Besides, the consideration of the aspect of the four faces of Durisolchip boards type gives the possibility to leave visible main facades naturally decorated.

\subsection{Constitutive Elements}

\section{New ameliorations}

The modification brings to traditional masonry consists of one part to give a new aspect to the parement, to cancel the use of coffering woods in the realization of the vertical and horizontal chaining slinks, to ensure the cohesion of 


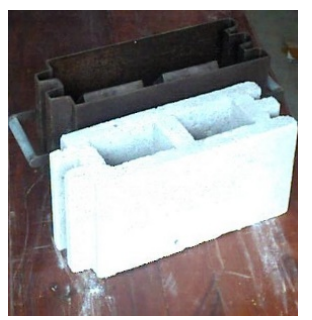

(a)

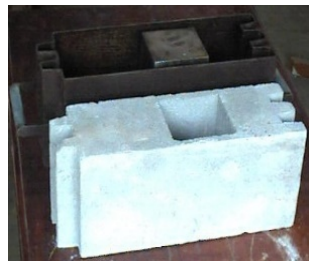

(e)

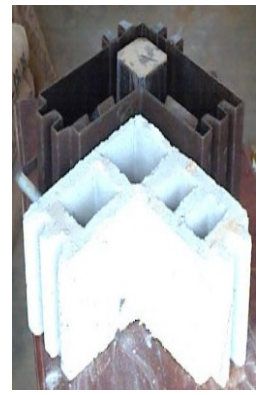

(i)

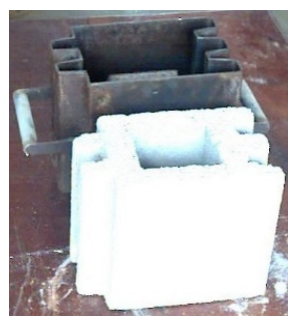

(b)

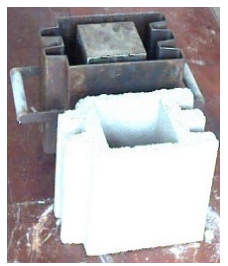

(f)

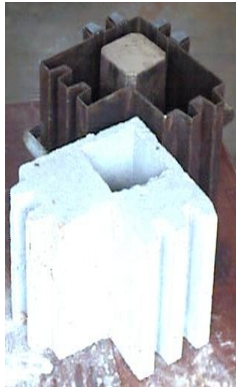

(j)

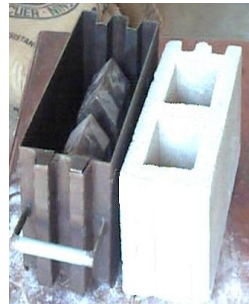

(c)

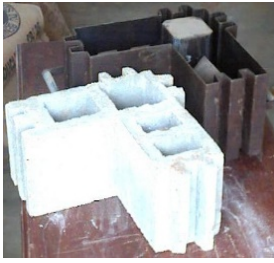

(g)

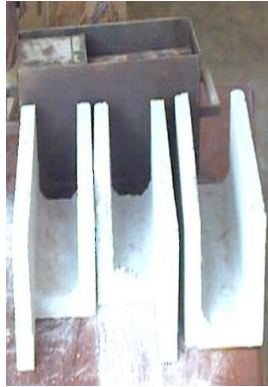

(k)

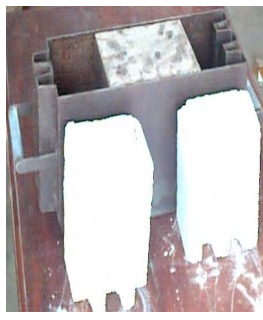

(d)

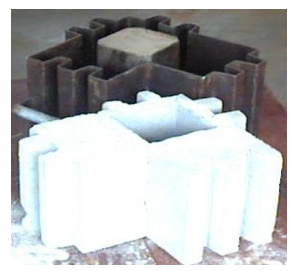

(h)

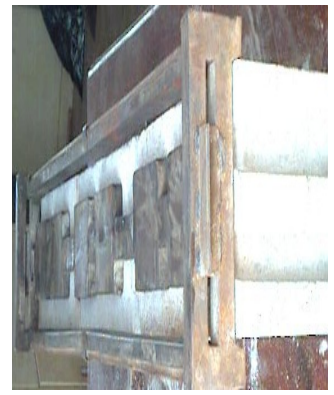

(l)

Figure 1. Chipboards and fabrication equipment.

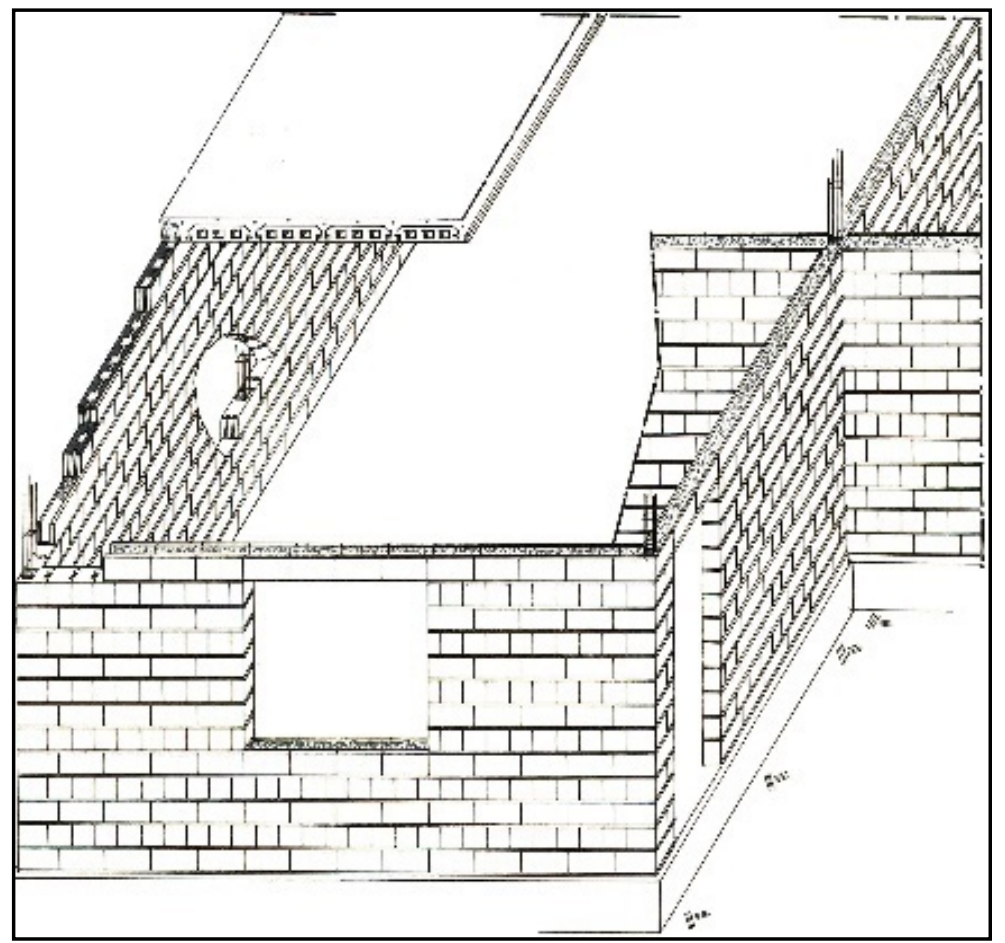

Figure 2. Masonries with eviscerated bed joints and hollow vertical joints. 


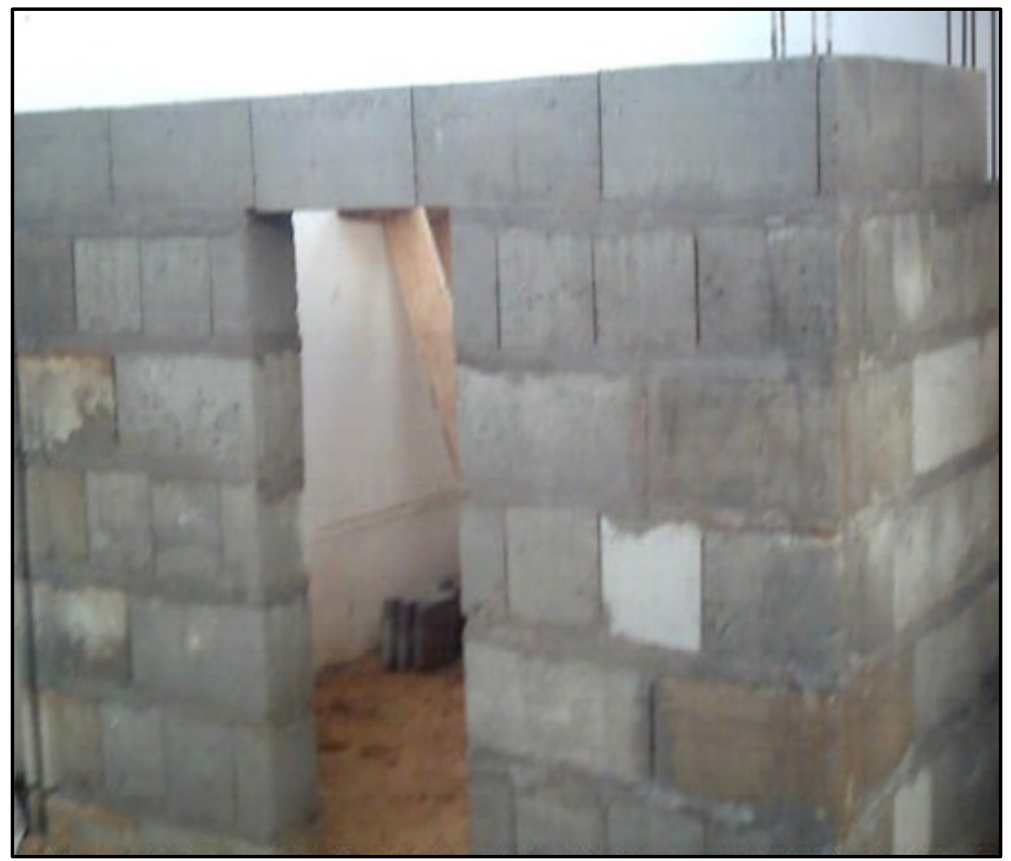

Figure 3. Same masonries in place: practical case.

chipboards by dry verticals and eviscerated horizontals joints. The objectives of that modification are summarized like the following:

- Reduce the waste and the quantity of the main material used in the build-up, (or the jointment) and the execution of enduits

- Realize wall with net decored parement with the possibility to have regular joints like those of blocks walls with compressed ground (BTC), showing French apparat;

- Increase thermic performances of walls in the habitations (Figure 2 and Figure 3).

\subsection{Principle and Use Domains of Walls}

The process of wall with special blocks that is concerned here is a type of masonry obtained by arrangement of chipboards which fit some into others, set by set. On odd row sets are disposed chipboards of $40 \mathrm{~cm}$ current length, and on even row sets are chipboards of $20 \mathrm{~cm}$ length (Figure 1(a) and Figure 1(b)). Disposed like that, the system offers a french apparat type. The blocks are tied by fits system which cancel vertical jointment.

Concerning sets, they are linked some to others by a regular layer of $2 \mathrm{~cm}$ thickness cement mortar put in place by a gabarit. The zones on which overlap the hollows of chipboards communicate between them by heavy losses; which improve thermic performances of wall, because of the pipe which exists between the various pockets of air. This process cancels coffering wood and uses special blocks designed for the molding of the concrete of vertical and horizontal stiffeners. It should be noted that all the blocs are intended for the construction of completely calepined walls where the breakage are not allowed. Then, any con- 
struction project using interlocked blocs must firstly take to account geometrical characteristics of chipboards when designing the structure.

The process so presented is intended to be used in the realization of bearing walls or not, in all types of current constructions like individual houses, public buildings, buildings for commercial, industrial, agricultural uses, refugee camps, offices and stores for construction sites.

Finally, we would want to remind that the construction system with vertical dry and horizontal evided joints is conformed to NFP 13,301 to 14,306 standards and to the dispositions of DTU 20.1. The dimensional tighter of special blocks never exceeds the tolerance of the standard NF $(+/-1 \mathrm{~mm}$ on each of the three sizes), allow the use of dry vertical joints [8].

\section{Methodology of Simulation}

\subsection{Principle}

Traditionally, simulation is based on finite elements method. The progress can be structured as follows [9] [10]:

1) Definition of displacement field $u(x, t)$ and deformation field $e(x, t)$, meshing which is made by four-node elements with a discontinuity placed in the center of the element.

2) Besides the usual interpolation of the field of displacement, has just stacked a function of called incompatible mode $\mathrm{M}(\mathrm{x})$ as shown below (Figure 4).

3) The discreet formulation of the problem fonds a usual shape. The equations, afterward are boring and complex to solve.

This awareness led to us to look for mathematical tools able to do the same work and for a lesser cost: Solidworks/COSMOS Works satisfies our expectations.

\subsection{Context}

The work was led on Solidworks as for the assembly of system and on Cosmos Works as for the simulation of the loading, both being connected by an interface.

For any study defined by means of interface between SolidWorks and CosmosWorks, parameters are producted; the meshing is then done (here it is

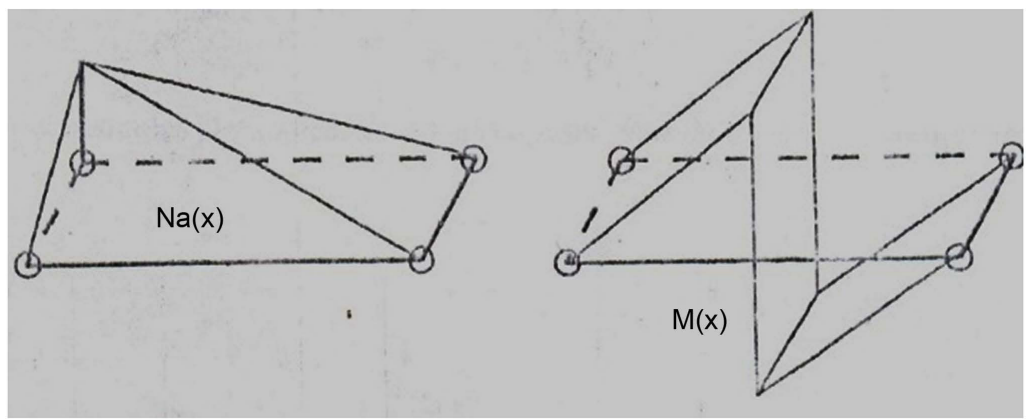

Figure 4. Incompatibles modes. 
volumetric elements with three nodes), then the big matrix of rigidity is defined, the system of equations is put and solved and finally the results are presented in digital form and under graphic shape.

The shape of results being with difficulty exploitable, we crossed them then on MATLAB to obtain curves more usual and easy to run.

The main difficulty here is to design the geometry of the model with exactly the same constraints and dimensions like the real model, and to define parameters to introduce for a heterogenous material like masonry [11] [12] [13]. Once that difficulty solved, the software follows exactly the steps of finite element method and we obtain the solution in terms of distribution of nodal constraints, displacements, distorsions, the deformed and an overview of the design control.

\subsection{Simplifying Hypotheses}

\section{- Geometry of chipboards.}

The dimensions of the fittings were slightly corrected to allow the perfect interweaving of the male parts in the female parts. Also, alveoli underwent a light modification of shape at the level of their headland in particular (the shape was made rectangular, instead of the trapezoidal shape).

- Dimensions of the low wall:

To move closer to us as close as possible to the reality while taking into account possibilities limited by the computer, we worked on low walls of $2.40 \mathrm{~m}$ length and $1.30 \mathrm{~m}$ height; what corresponds for example to a wall under window. For the rises, we respected the technique of implementation usually used in the practice.

\section{- Mechanical characteristics.}

For mechanical characterics we based ourselves on the works led before [14] and after especially on G.N. PANDE [11], Patrick DELMOTTE [6] and Jean Baptiste Colliat [8] works. We then considered the average characteristics of the assembled masonries.

The characteristics used are those obtain after trial campaigns on the assembled masonries and after theoretical calculations on the mathematical models of CSTB:

- Elasticity module: $\mathrm{E}=3500 \mathrm{~N} / \mathrm{mm}^{2}$

- Cutting module: $\mathrm{G}=224 \mathrm{~N} / \mathrm{mm}^{2}$

- Density: $\rho=2200 \mathrm{~kg} / \mathrm{m}^{3}$

- Poisson coefficient: $\mathrm{n}=0.20$

- Elastic limit: $\mathrm{E}_{\mathrm{o}}=0.00026 \mathrm{~N} / \mathrm{mm}^{2}$

- Tractionlimit: $\mathrm{f}_{\mathrm{t}}=0.13 \mathrm{~N} / \mathrm{mm}^{2}$

- Compressionlimit: $f_{c}=9.85 \mathrm{~N} / \mathrm{mm}^{2}$

- Cutting limit: $\mathrm{f}_{\mathrm{t}}=0.30 \mathrm{~N} / \mathrm{mm}^{2}$

- Coefficient of thermal expansion: $\alpha=\rho \cdot(c / k)=0.66$

- Thermal conductivity: $\lambda=1.0 \mathrm{w} /(\mathrm{mK})\left(\right.$ concreteor bricks à $\left.20^{\circ} \mathrm{C}\right)$

- Mass thermal capacity: $\mathrm{c}=0.88 \mathrm{KJ} /(\mathrm{kgK})$ (concrete)

- Radiation constant: $\mathrm{c}=5.30 \times 10^{-8} \mathrm{w} /\left(\mathrm{m}^{2} \cdot \mathrm{K}^{4}\right)$ (wall) 


\section{- Borders.}

The trial low wall is supposed perfectly embedded on its basis.

\section{- Loading.}

The low wall is loaded in his plan by a variable surface pressure (to conform to the tries of the same nature made by the CSTB); we then observe constraints, displacements, distorsions, deformed and the design control. But for reason of the espace limits, we just show some results here.

\section{Results and Interpretation}

\subsection{Progress Method}

Considering a low wall as indicated up there, after loading, we observe the general behavior.

The simulation comports many steps:

- Definition of one study;

- Definition of loading and border conditions (embedding at the bottom);

- Introduction of properties and characteristics of material (masonry);

- Meshing: it is volumic with four nodes, we choose to increase the precision of the model by choosing a fine meshing with global size of $42.2180 \mathrm{~mm}$ and tolerance of $2.1109 \mathrm{~mm}$ for the new wall; that needs approximately $15 \mathrm{mi}$ nutes per simulation. For comparison needs, the big meshing have a global size of $156.8100 \mathrm{~mm}$ per element and tolerance of $7.8405 \mathrm{~mm}$. We have to take note that the precision increases with the finess of meshing.

- Execution: computer put equations system, build the big rigidly matrix, solve the equations and calculate constraints according to Von Mises citeria.

As illustration, for one loading of the new wall, the meshing gives 86,636 elements, 19,390 peripheral nodes and 414,399 liberty degree. We can imagine the size of such system which is nevertheless solved in 54 seconds! This justifies the interest of the used software.

- The elaboration of report and the observation of results are then made.

- Finally, results are passed in MATLAB in order to draw curves and to filter.

In order to compare the behavior of both walls, we did the same simulation at similar conditions for walls with traditional chipboards, and results are then compared.

For all those simulations, the loads used are inside a plage which comport break limit in order to observe behavior around that limit.

Besides, the meshing being geometric, it is just presented once for each type of wall.

\subsection{Loading on Normal Strength}

\subsubsection{Case of New Wall (Solidworks Page)}

On this model, simulation gives 12,348 elements, 3203 peripheral nodes, 63,861

liberty degrees. The loading is show as Figure 5.

And the meshing is showed as below (Figure 6). 


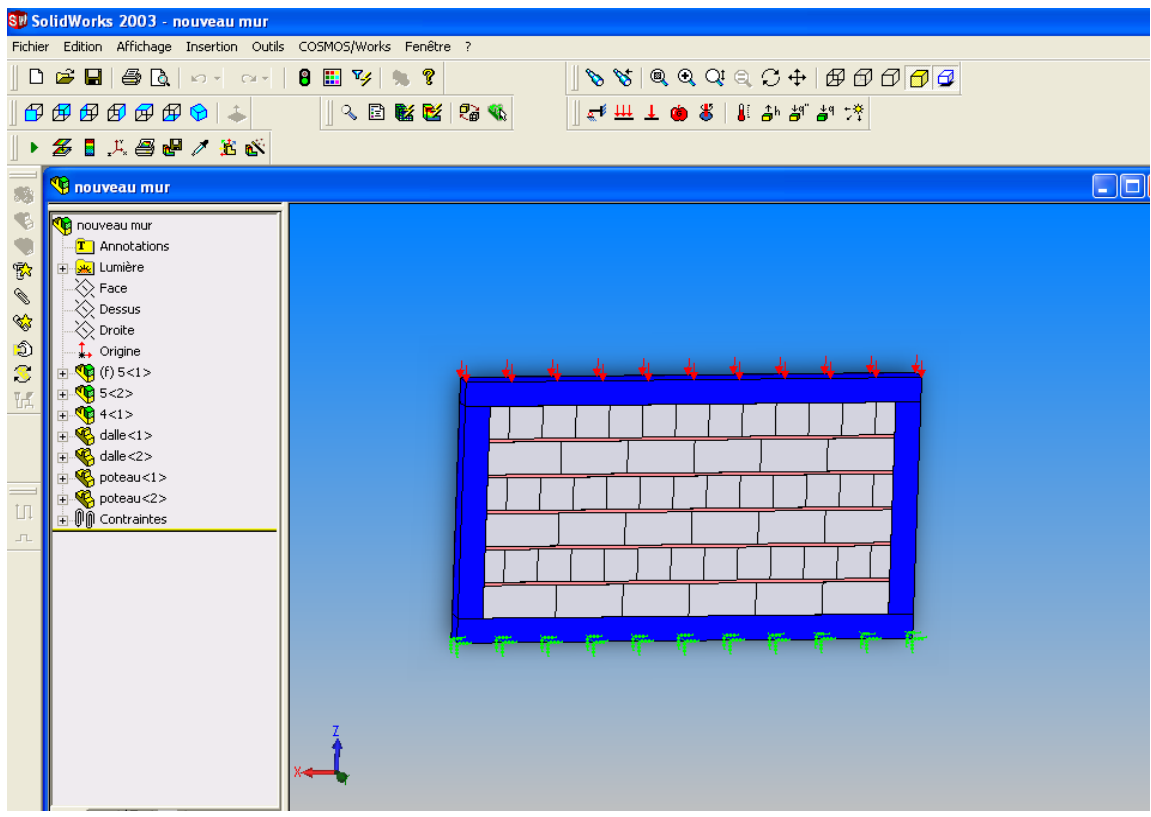

Figure 5. New wall submitted to normal strength ready for simulation.

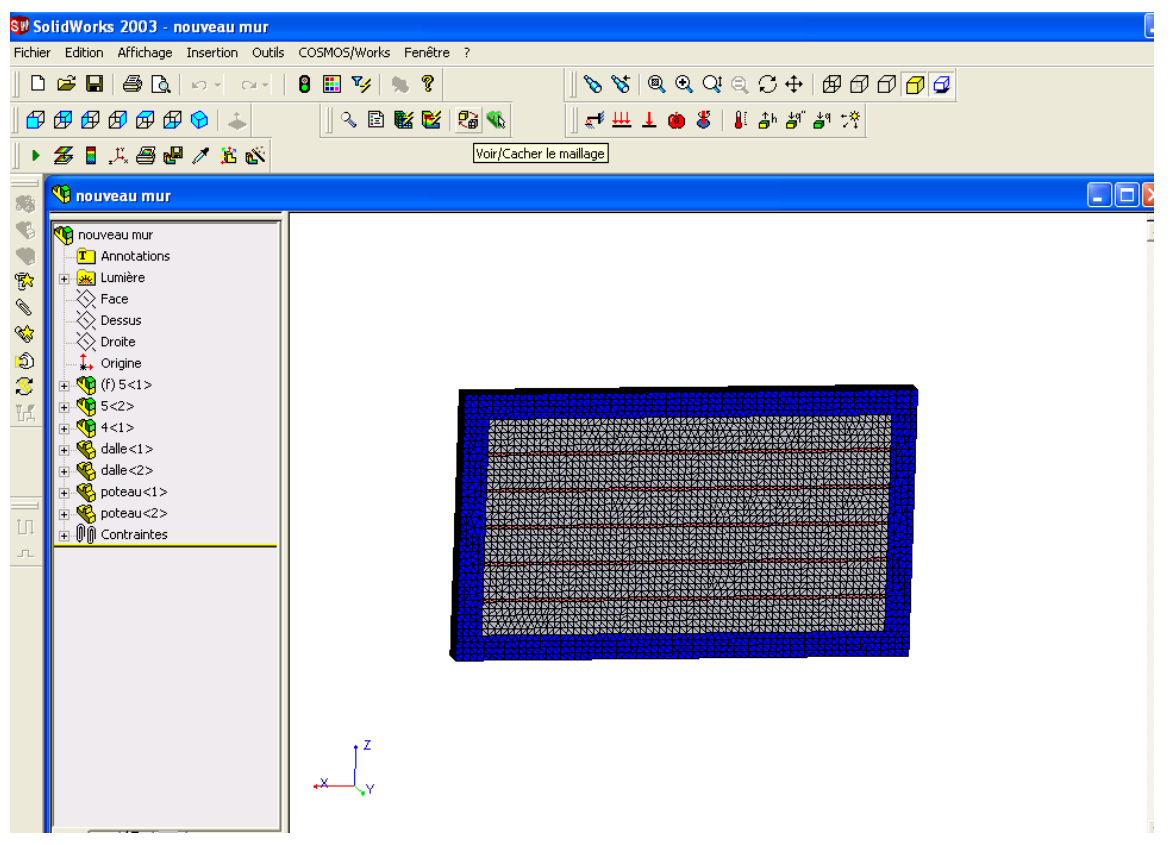

Figure 6. Meshing of new wall.

Lets us remember that the meshing is volumic with four nodes, and for the case presented by Figure 6, the given configuration corresponds at one fine meshing. We chose that option for more precision in our simulations.

Solve the resulted big equation system gives the following results (all values are given with International System of Unities) presented in Table 1.

N.B: The chosen load rate, while random, corresponds at the beginning of the zone where the effort has a significant influence on the model.

From those results, treated on MATLAB, we obtained the following behaviors 
Table 1. Results of simulations of new wall under normal effort.

\begin{tabular}{|c|c|c|c|c|c|c|c|c|c|c|c|c|c|c|c|}
\hline Force $\times 10^{6} \mathrm{~N} / \mathrm{m}^{2}$ & 30 & 35 & 40 & 45 & 50 & 55 & 60 & 65 & 70 & 75 & 80 & 85 & 90 & 95 & 100 \\
\hline $\begin{array}{l}\text { Maximal constraint } \\
\text { of VON } \\
\text { MISES } \times 10^{8} \mathrm{~N} / \mathrm{m}^{2}\end{array}$ & 1.125 & 1.314 & 1.502 & 1.690 & 1.878 & 2.065 & 2.252 & 2.44 & 2.628 & 2.815 & 3.003 & 3.191 & 3.378 & 3.566 & 3.754 \\
\hline $\begin{array}{c}\text { Maximal } \\
\text { displacement } \times 10^{-4} \mathrm{~m}\end{array}$ & 3.482 & 4.063 & 4.643 & 5.224 & 5.804 & 6.385 & 6.965 & 7.546 & 8.126 & 8.706 & 9.287 & 9.867 & 10.45 & 11.03 & 11.61 \\
\hline $\begin{array}{c}\text { Maximal } \\
\text { deformation } \times 10^{-4} \mathrm{~m}\end{array}$ & 2.905 & 3.390 & 3.874 & 4.358 & 4.842 & 5.327 & 5.805 & 6.289 & 6.772 & 7.256 & 7.740 & 8.224 & 8.707 & 9.191 & 9.675 \\
\hline $\begin{array}{c}\text { Limit of } \\
\text { failure } \times 10^{8} \mathrm{~N} / \mathrm{m}^{2}\end{array}$ & & & & & & & & 1.723 & & & & & & & \\
\hline
\end{tabular}

(forms of results from Cosmos):

1) Maximal constraint

The variation of maximal constraint under normal effort for new masonries is like Figure 7.

We note that under normal load, the model continues to have an elastic behavior beyond the limit of rupture. There is one evident proportional relationship between the load and the maximal constraint.

2) Resultant displacement

The resultant displacement for that case is like shown in Figure 8.

Resultant displacements increase quickly with the load and they are important, and their values reach the millimeter.

3) Variation of Maximal deformation

And the variation of the maximal deformation is represented in Figure 9.

Deformation variation is like maximal constraint, attesting the existing of a proportional relationship between those two values. The values of deformations reach shyhtly the millimeter.

Being on MATLAB, we could intent to filtrate our results in order to cancel noise; but the work been based on numerical simulation, we thought that one has a very small stochastic character in an experimental campaign for example. We then didn't filtrate the results.

\subsubsection{Case of Traditional Wall (Solidworks Page)}

The same loads combinations are the used for traditional wall.

Let's consider now a short wall with classic chipboards (Figure 10) with same dimensions and loaded in the same conditions as the short wall with special chipboards (new wall) (Figure 5). The fine meshing is done here during three minutes and gives elements with global size of $41.704 \mathrm{~mm}$ and a tolerance of $2.0852 \mathrm{~mm}$. The running of this model gives 70,029 elements, 17,176 peripherical nodes and 350,082 liberty degree (Figure 11). To solve the big equations system that resulted and calculate constraints, we just need five minutes!

Meanwhile the loading and the conditions at the limits are the same, the meshing is different in terms of number of elements, from the one obtained for 


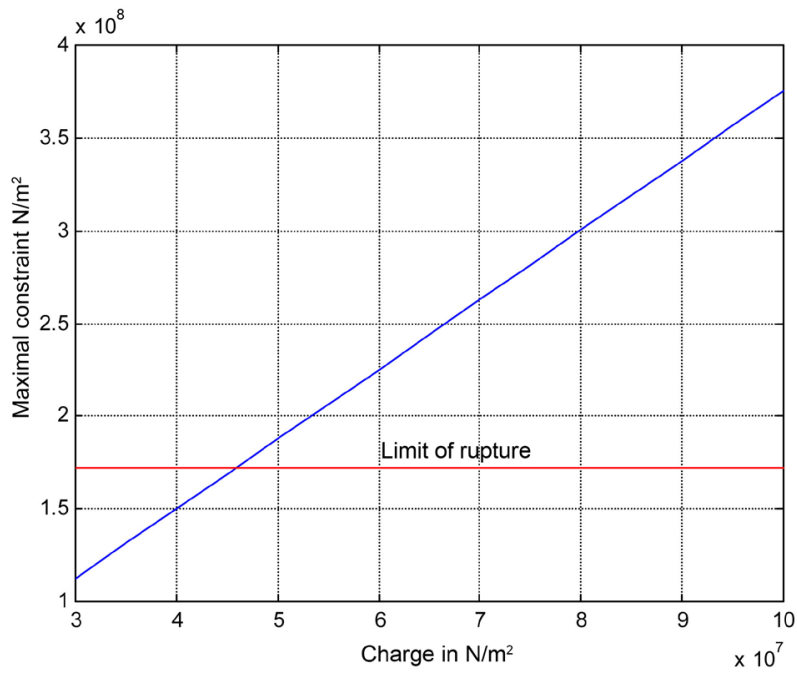

Figure 7. Variation of maximal constraint under normal effort.

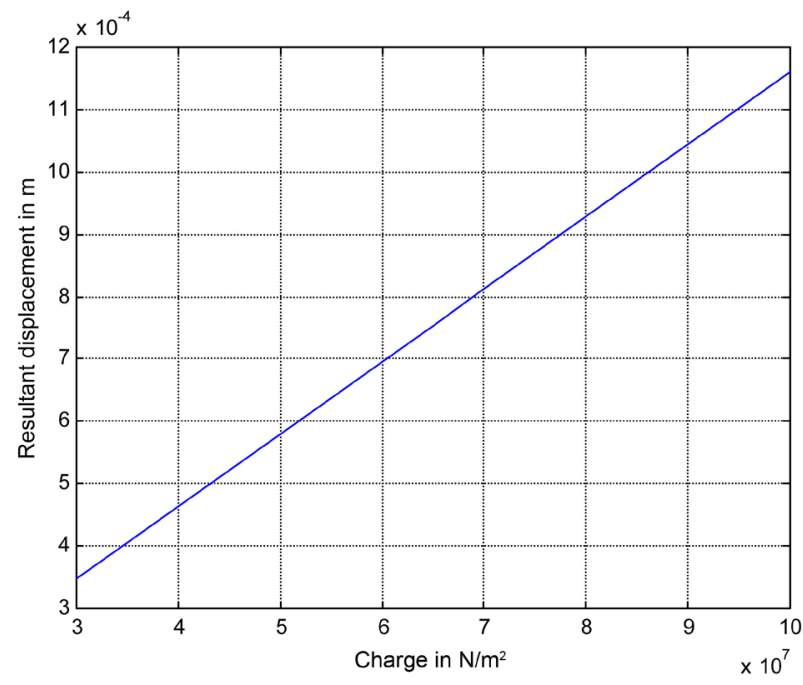

Figure 8. Variation of resultant displacement under normal effort.

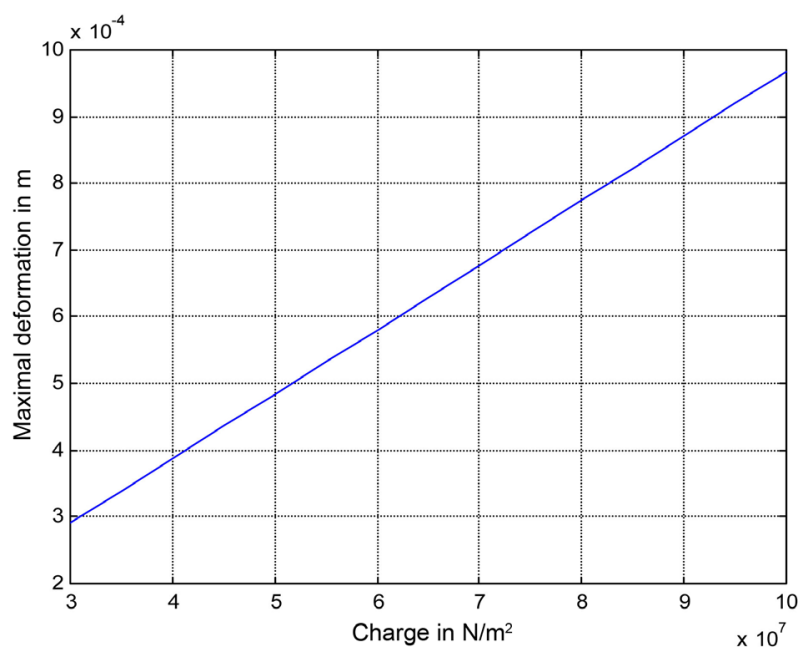

Figure 9. Variation of maximal deformation under normal effort. 


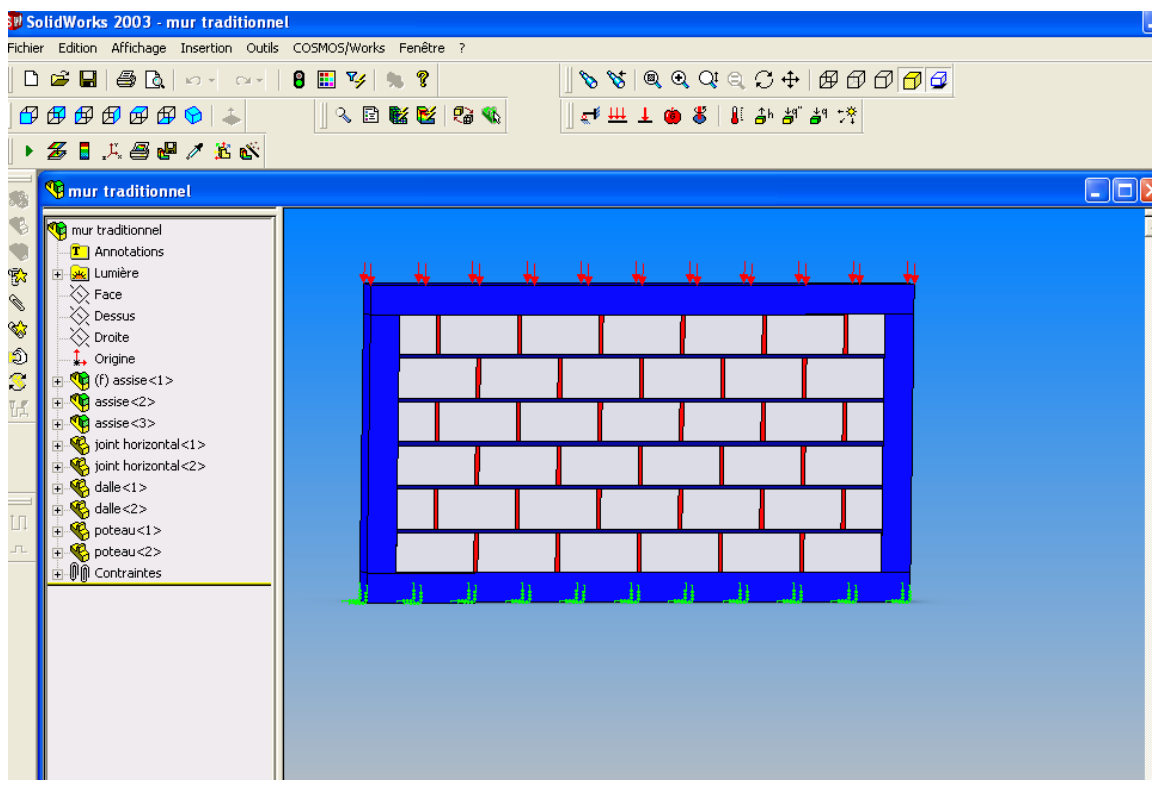

Figure 10. Loaded traditional wall ready to test.

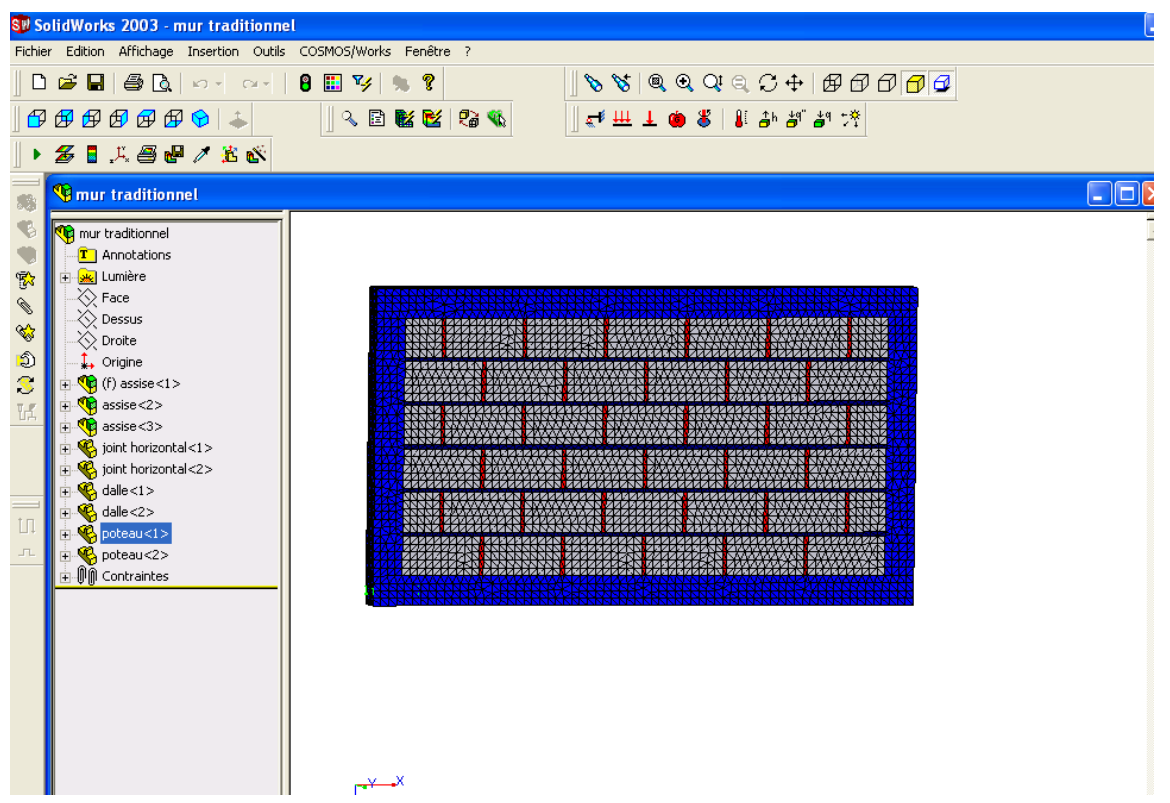

Figure 11. Traditional wall meshed.

the first short wall. The equations system to solve is different and we observe the following variations presented in Table 2.

We note that maximal constraints increase less quickly than those for the new wall. In contrary, the resultants displacement increase more quickly; we can then envisaged the failure of this model before the new one. For example, under a load of $10^{7} \mathrm{~N} / \mathrm{m}^{2}$, maximal deformation of the new wall is $0.967 \mathrm{~mm}$, while the one of the traditional wall is $1.041 \mathrm{~mm}$.

We shall ask ourselves why a model which develops higher constraints can generate displacements and deformations less than those generate by the model 
Table 2. Results of simulations on traditional wall under normal effort.

\begin{tabular}{|c|c|c|c|c|c|c|c|c|c|c|c|c|c|c|c|}
\hline Force $\times 10^{6} \mathrm{~N} / \mathrm{m}^{2}$ & 30 & 35 & 40 & 45 & 50 & 55 & 60 & 65 & 70 & 75 & 80 & 85 & 90 & 95 & 100 \\
\hline \multicolumn{16}{|l|}{ Maximal constraint } \\
\hline of VON & 0.885 & 1.033 & 1.180 & 1.328 & 1.476 & 1.623 & 1.771 & 1.918 & 2.066 & 2.213 & 2.361 & 2.509 & 2.656 & 2.804 & 2.951 \\
\hline \multicolumn{16}{|l|}{ MISES $\times 10^{8} \mathrm{~N} / \mathrm{m}^{2}$} \\
\hline $\begin{array}{c}\text { Displacement } \\
\text { maximal } \times 10^{-4} \mathrm{~m}\end{array}$ & 3.831 & 4.470 & 5.108 & 5.747 & 6.385 & 7.024 & 7.662 & 8.301 & 8.939 & 9.578 & 10.22 & 10.85 & 11.49 & 12.13 & 12.77 \\
\hline $\begin{array}{c}\text { Maximal } \\
\text { deformation } \times 10^{-4} \mathrm{~m}\end{array}$ & 3.124 & 3.645 & 4.165 & 4.686 & 5.207 & 5.727 & 6.248 & 6.769 & 7.289 & 7.810 & 8.331 & 8.851 & 9.372 & 9.892 & 10.41 \\
\hline $\begin{array}{l}\text { Limitof rupture } \\
\times 10^{8} \mathrm{~N} / \mathrm{m}^{2}\end{array}$ & & & & & & & & 1.723 & & & & & & & \\
\hline
\end{tabular}

which develops small constraints. This can be explained by the fact that vertical dry joints in the new wall constitute areas of dissipation of energy of deformation.

In summary, the behaviors of constraints, displacements and deformations of the traditional wall under normal effort are the following:

1) Maximal constraint

The maximal constraint in this case is represented by Figure 12 .

Here, constraints developed are less important, the increasing is also slower.

2) Resultant Displacement

The resultant displacement is practically proportional to load as shown on Figure 13.

The displacements are more important here than those on the new wall.

3) Maximal deformation

The maximal deformation here is represented by Figure 14 .

In the same way, deformations are more important here than those for the new model.

\subsubsection{Conclusion on Those Simulations}

Considering the results obtained on Cosmos Works on the two types of mansonries, we note that the repartition of constraints is more uniform on traditional wall, in contrary, on new wall, odd sets are the place of big constraints. More, the new wall develops bigger constraints than the traditional wall. This last aspect is explained by the presence of vertical dry joints.

Concerning displacements, we noted that the values move more quickly on traditional wall than on new wall.

For deformations, they are beyond a millimeter on traditional wall, in the same time, they are less than a millimeter on new wall.

As we have early noticed, this is linked to the dissipation of deformation energy at the level of vertical dry joints. We can then conclude that the new wall has a best behavior under normal effort, because it may arrive at failure point less quickly than the traditional wall. 


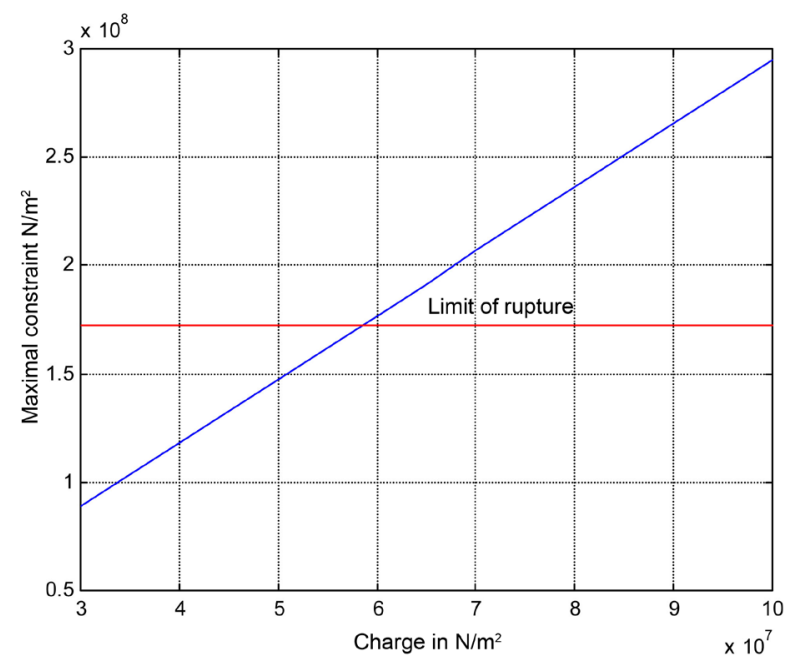

Figure 12. Variation of maximal constraint for traditional wall under normal effort.

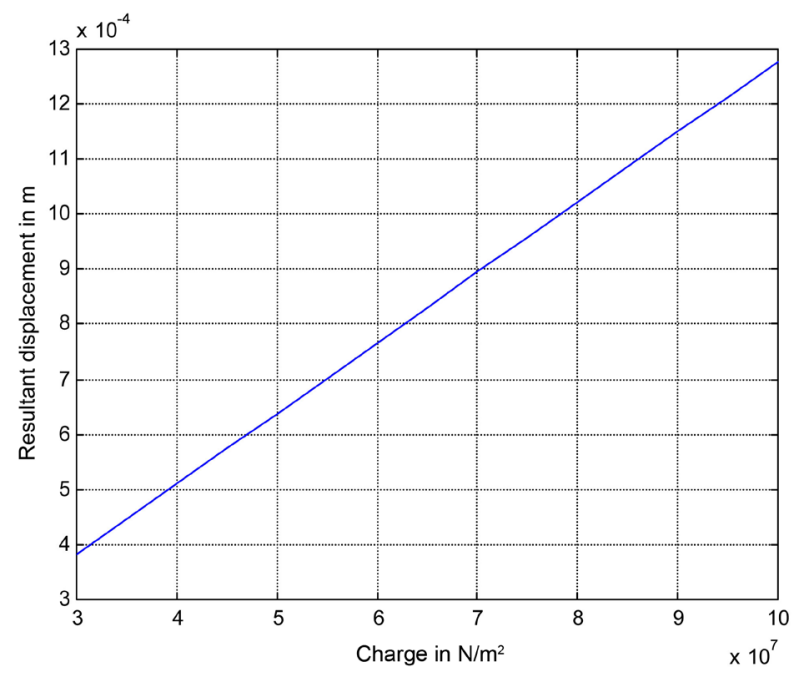

Figure 13. Variation of resultant displacement for traditional wall under normal effort.

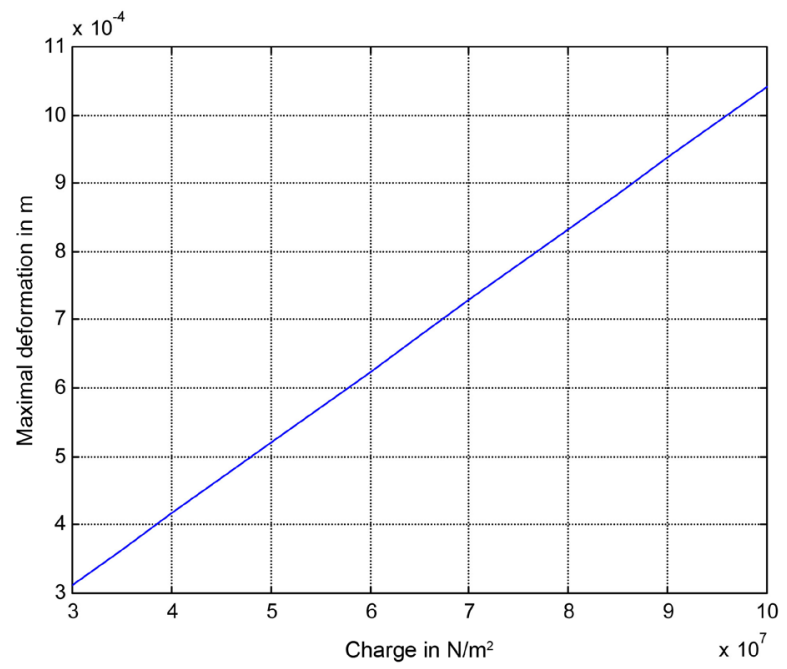

Figure 14. Variation of maximal deformation for traditional wall under normal effort. 


\subsection{Simulation on the New Wall under Vertical Load and Horizontal Punctual Load Applied on One Chipboard}

\subsubsection{Case of New Wall (Solidworks Page)}

In order to observe the resistance of the fits under horizontal punctual load on a chipboard, we have simulated the model as indicated by Figure 15. The short wall is entied on the two profile sides and it is loaded in its plan by a constant load of $3 \times 10^{6} \mathrm{~N} / \mathrm{m}^{2}$ and a punctual and variable horizontal load on a chipboard. That load can represent any object on the wall according to the TAN description [15]. The short wall with same dimensions and borders conditions like up there, we observe its behavior particularly the borders areas of the chipboard which is loaded horizontally.

The results obtained on a short wall of new chipboards are presented as follow (Table 3).

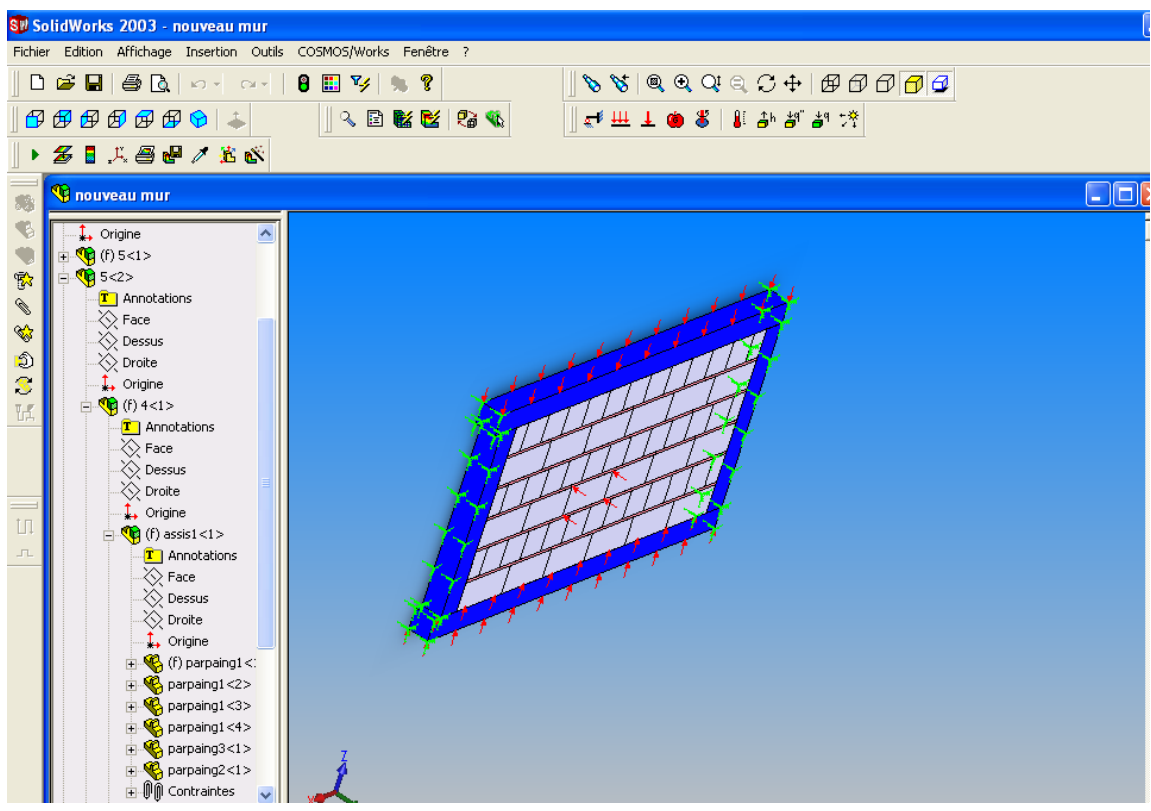

Figure 15. Simulation on the new wall under a constant vertical laod and apontual variable horizontal laod.

Table 3. Results of simulations on a chipboard of the new wall.

\begin{tabular}{cccccccccc}
\hline $\begin{array}{c}\text { Normal effort } \\
\times 10^{6} \mathrm{~N} / \mathrm{m}^{2}\end{array}$ \\
$\begin{array}{c}\text { Tangential } \\
\text { effort } \times 10^{5} \mathrm{~N} / \mathrm{m}^{2}\end{array}$
\end{tabular}


The graphs of behavior are presented as follow:

1) Maximal constraint

The variation of the maximal constraint is shown in Figure 16.

We note that an elastic behavior before the limit of failure and from the point of failure situated just after that limit. That's close to the conclusions of M. Dhanasekar for biaxial loading [16].

2) Resultant displacement

For the resultant displacement, the behavior is as follow (Figure 17).

We note one area of slow increasing and one area of big increasing with an inflexion at the level of the loading of $3 \times 10^{6} \mathrm{~N} / \mathrm{m}^{2}$; which could represent the loading of failure.

3) Maximal deformation

The maximal deformation is presented there (Figure 18).

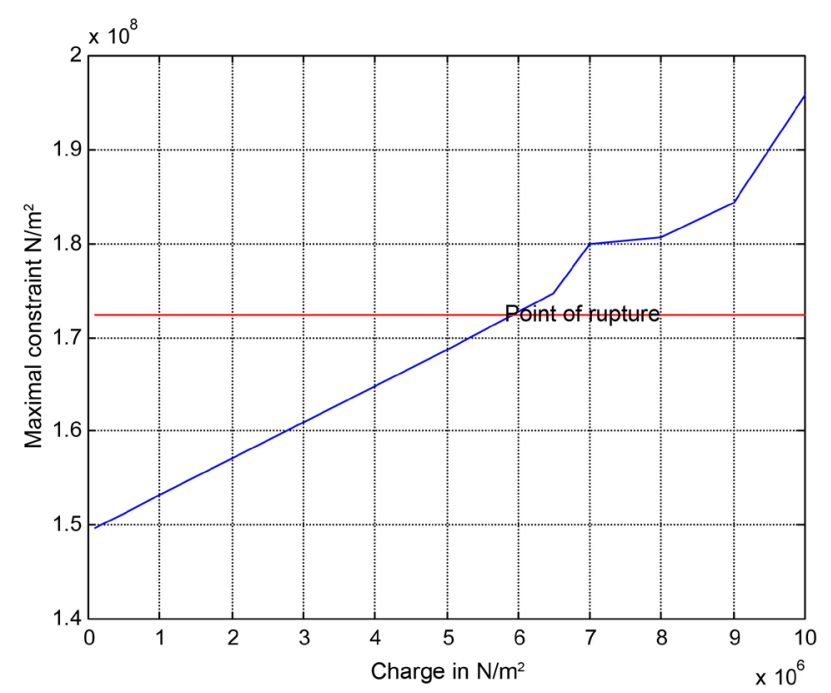

Figure 16. Variation of maximal constraints around chipboard of the new wall.

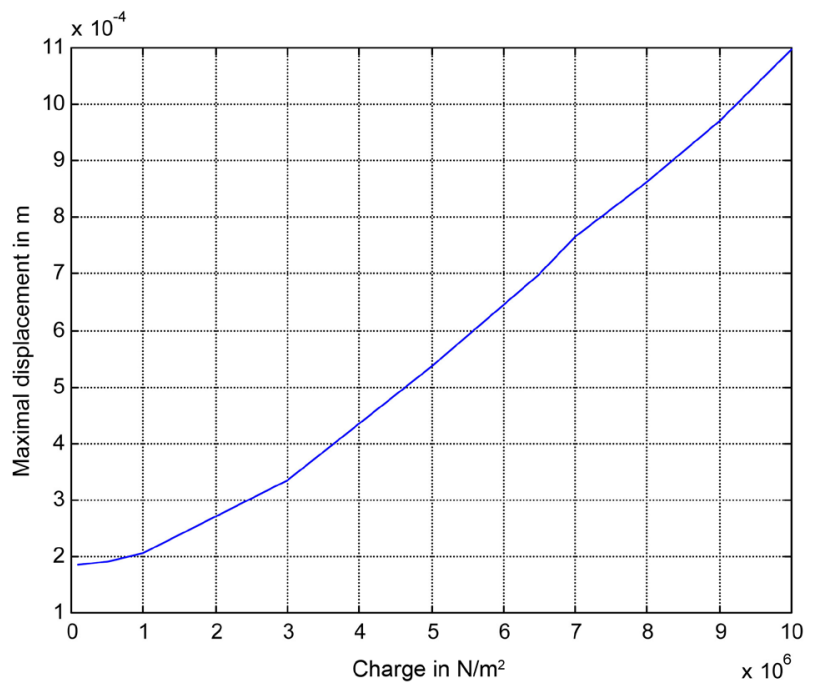

Figure 17. Variation of resultant displacement around a chipboard of the new wall. 


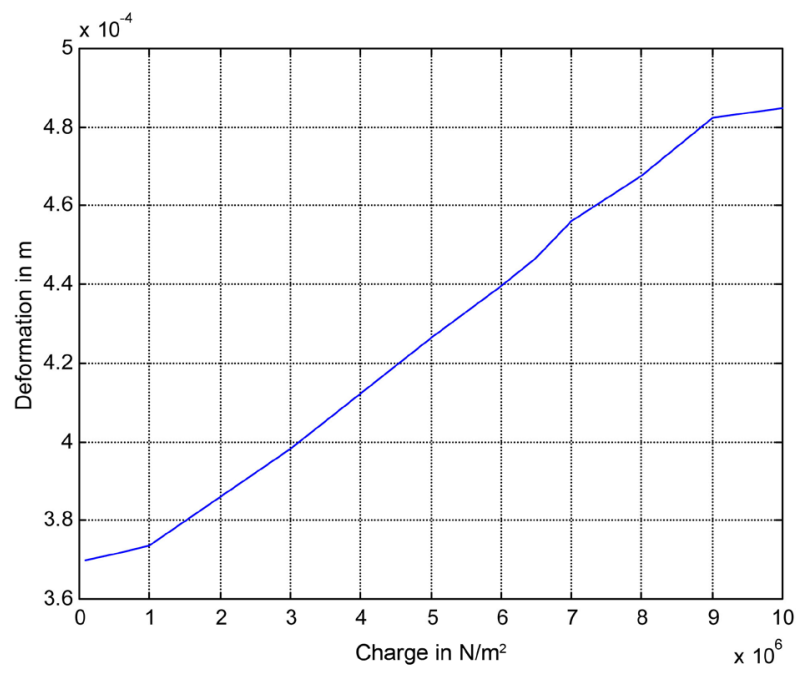

Figure 18. Variation of maximal deformation around a chipboard of the new wall.

Deformations have an inflexion around the loading of $10 \times 10^{6} \mathrm{~N} / \mathrm{m}^{2}$ and have a fast increasing; that loading could be that of failure. After that, the increasing becomes slow after the loading of $9 \times 10^{6} \mathrm{~N} / \mathrm{m}^{2}$. We can think that, at that moment, all joints have failed, there is any hollow inside the model and elements are each other in contact, then deformations increase slowly.

\subsubsection{Case of Traditional Wall (Solidworks Page)}

In order to have a comparative approach, a traditional wall with the same dimensions and the same conditions than the new wall is loaded (Figure 19); we then observe.

The results of simulation obtained on that short wall of traditional chipboards are presented as follow (Table 4).

1) Maximal constraint

For that loading situation, the variation of the maximal constraint is the following (Figure 20).

The curve presents many inflexion points with the growth of the increasing velocity at each time. Constraints are then developed progressively and faster and faster following the increasing of the loading.

2) Resultant displacement

Here, the resultant displacement is moving as represented by Figure 21 .

Displacements have a slow increasing first, then an inflexion at the loading of $10^{6} \mathrm{~N} / \mathrm{m}^{2}$ and after, a growth of the increasing velocity.

3) Maximal deformation

And the maximal deformation behavior is represented by Figure 22 .

Deformations have a regular increasing until the load of $9 \times 10^{6} \mathrm{~N} / \mathrm{m}^{2}$, after that, they have a growth of the increasing velocity.

\subsubsection{Conclusion on Those Simulations}

When we compare results obtained for the two cases, we can note that constraints are developed fastly at the beginning of the loading, but their growth is 


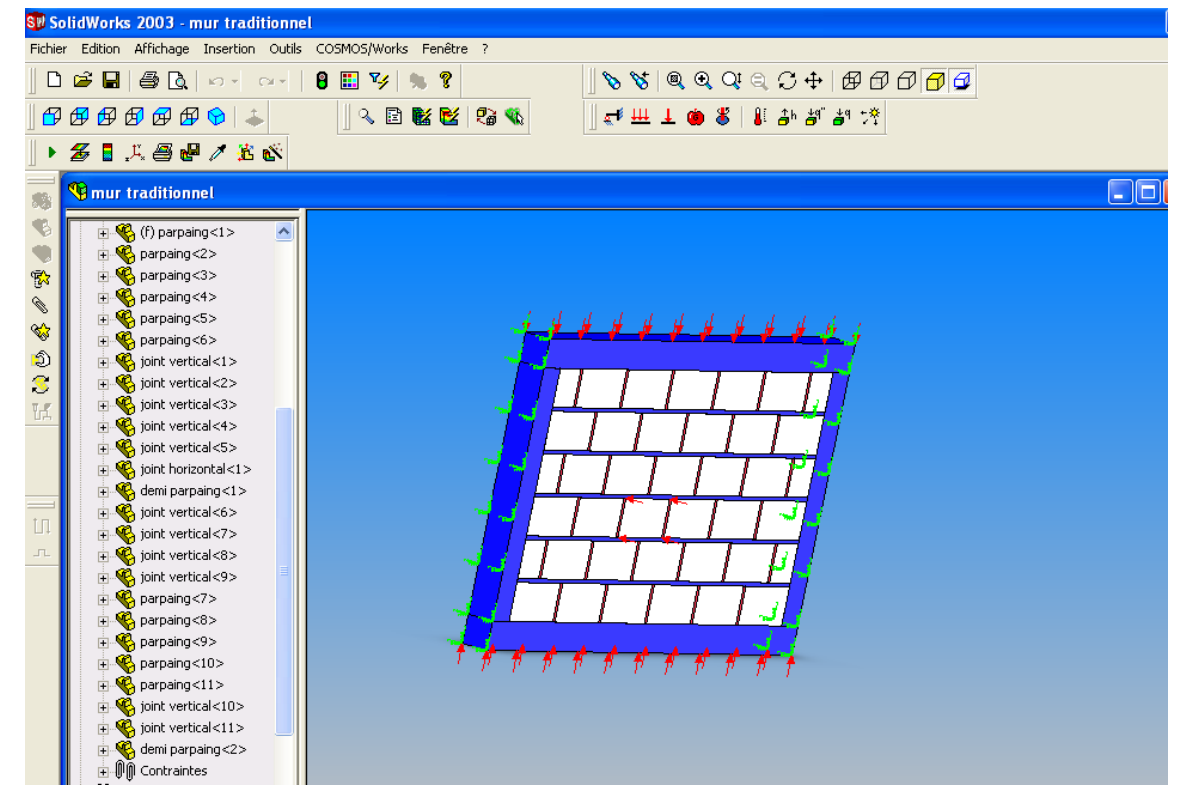

Figure 19. Simulation of traditional wall under vertical loading and a punctual horizontal loading on one chipboard.

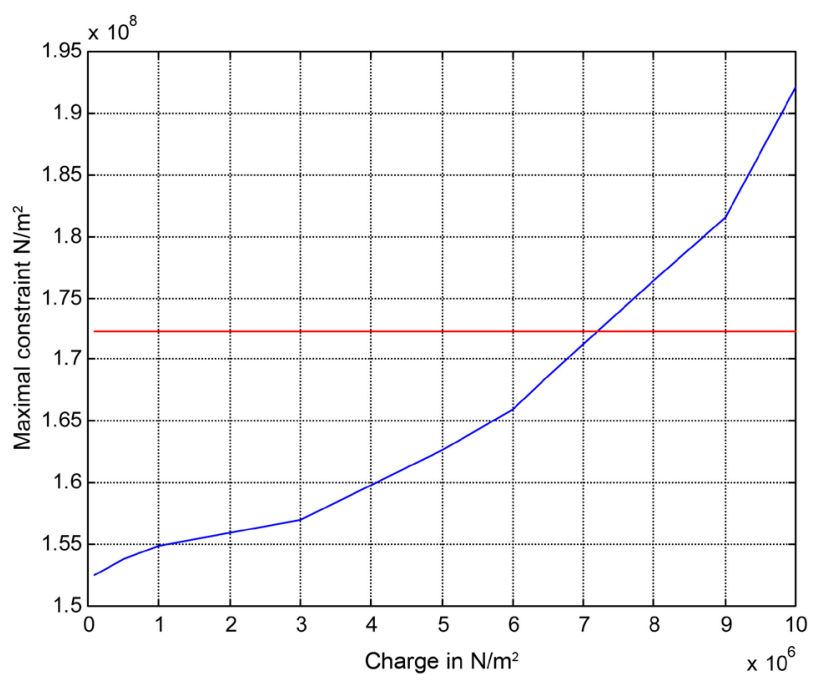

Figure 20. Maximal constraints around a chipboard of traditional wall.

Table 4. Results of simulations on chipboard of traditional wall.

\begin{tabular}{|c|c|c|c|c|c|c|c|c|c|c|c|}
\hline $\begin{array}{l}\text { Normal effort } \\
\times 10^{6} \mathrm{~N} / \mathrm{m}^{2}\end{array}$ & 30 & & & & & & & & & & \\
\hline $\begin{array}{c}\text { Tangential } \\
\text { effort } \times 10^{5} \mathrm{~N} / \mathrm{m}^{2}\end{array}$ & 1 & 5 & 10 & 30 & 50 & 60 & 65 & 70 & 80 & 90 & 100 \\
\hline $\begin{array}{c}\text { Maximal } \\
\text { constraint } \times 10^{8} \mathrm{~N} / \mathrm{m}^{2}\end{array}$ & 1.525 & 1.538 & 1.549 & 1.570 & 1.627 & 1.660 & 1.686 & 1.712 & 1.764 & 1.816 & 1.921 \\
\hline $\begin{array}{c}\text { Maximal } \\
\text { displacement } \times 10^{-4} \mathrm{~m}\end{array}$ & 1.998 & 2.069 & 2.273 & 3.812 & 6.217 & 7.476 & 8.105 & 8.735 & 9.995 & 10.125 & 10.251 \\
\hline $\begin{array}{c}\text { Maximal } \\
\text { deformation } \times 10^{-4} \mathrm{~m}\end{array}$ & 4.295 & 4.338 & 4.391 & 4.606 & 4.822 & 4.931 & 4.985 & 5.039 & 5.148 & 5.257 & 5.454 \\
\hline
\end{tabular}




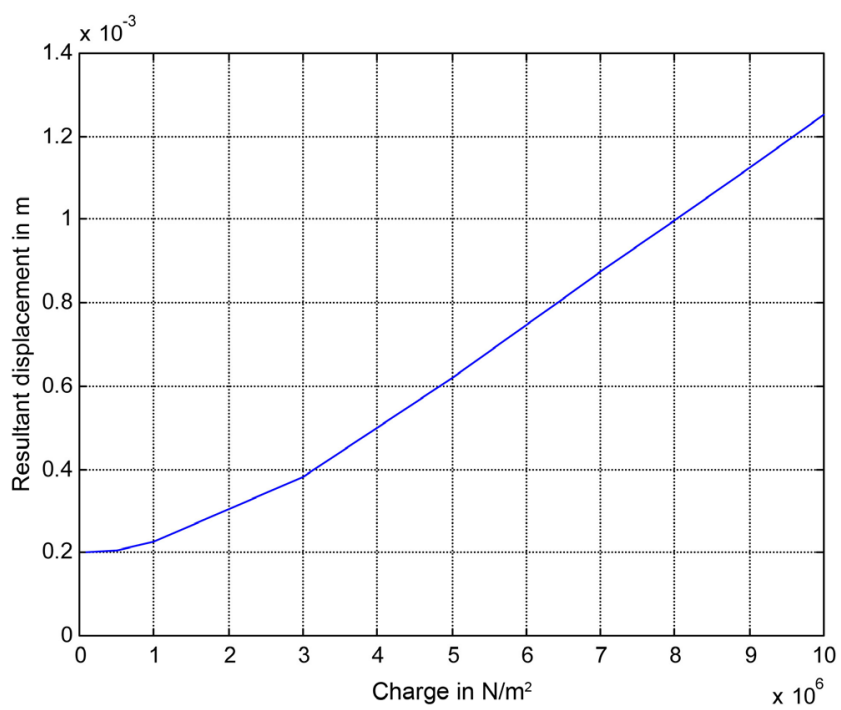

Figure 21. Resultant displacements around a chipboard of traditional wall.

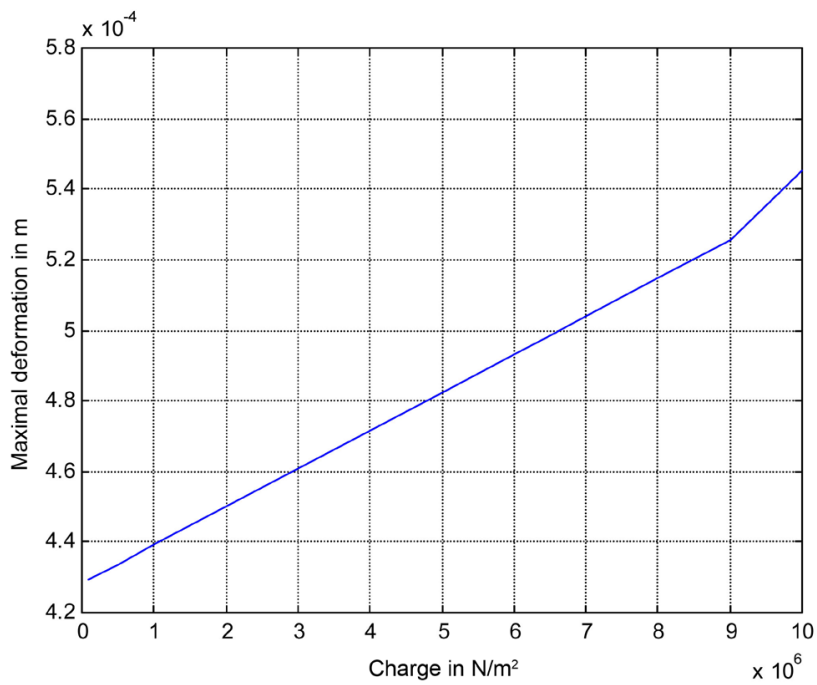

Figure 22. Variation of deformation around chipboard of traditional wall.

slow in contrary of constraints in the new wall which reach big values quickly.

Those results show when loaded as up there, the masonries of the new model have a least behavior than traditional masonries; that is due to fits used. Then, that system has a bad behavior when submitted to impact loads or horizontal loads on a chipboard.

\subsection{Simulation under Composed Loading}

\subsubsection{Simulation of the Behavior of the New Wall under Composed Loading}

Before trials under seismic loads, we have submitted the short walls under normal fix effort of $30 \times 10^{6} \mathrm{~N} / \mathrm{m}^{2}$, and a horizontal variable loading at the head of the wall (Figure 23) according to LOURENCO [17].

We then observe the following results (Table 5). 
Table 5. Results of simulations on new wall under composed loading.

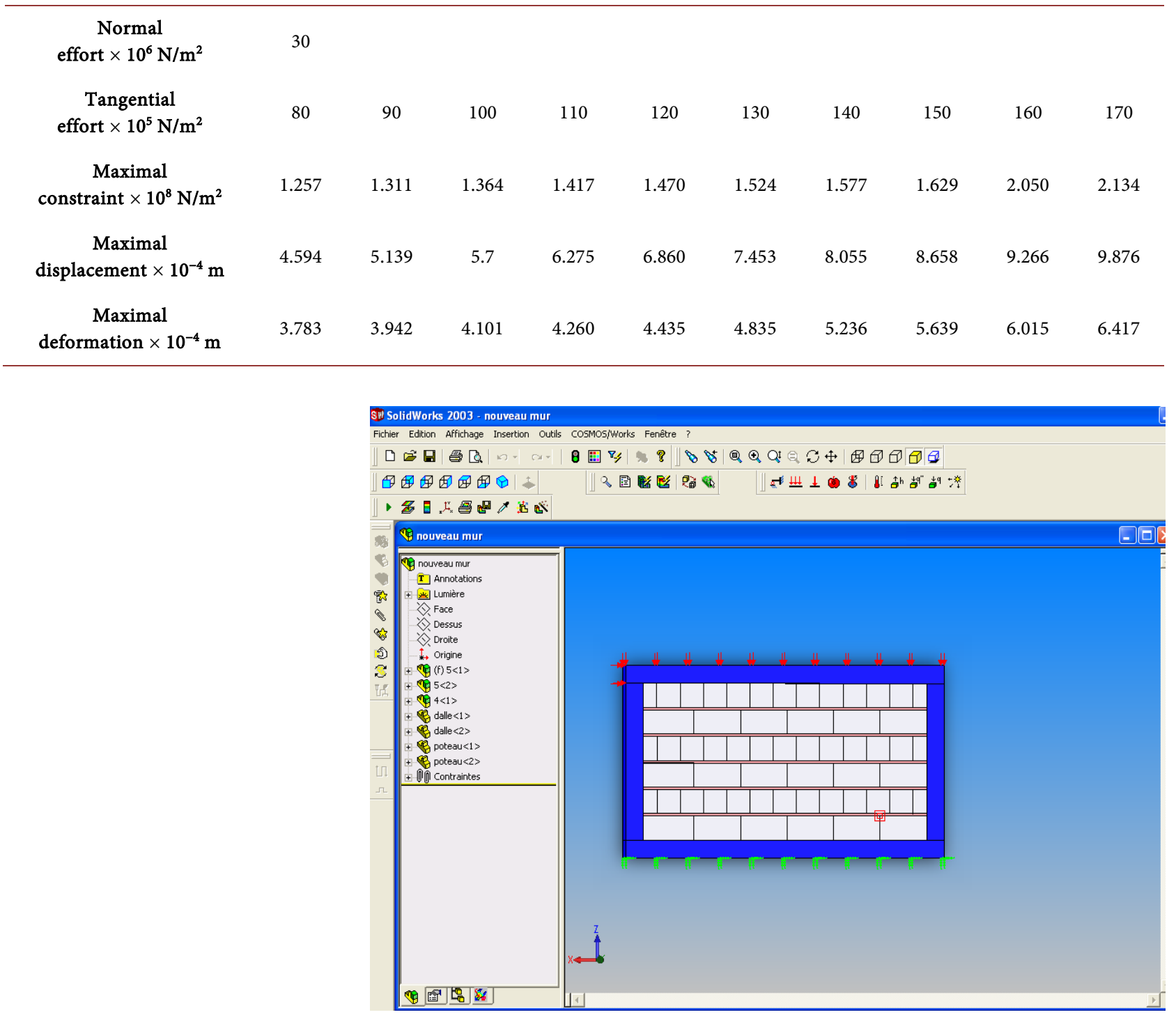

Figure 23. New wall under composed solicitations.

\section{1) Maximal constraint}

The variation of the maximal constraint is then (Figure 24).

We observe a point of failure situated before the failure limit (load of $1.5 \times 10^{8}$ $\mathrm{N} / \mathrm{m}^{2}$ ) as shown in Figure 24.

2) Resultant displacement

The variation of the resultant displacement is (Figure 25).

Displacements grow very fastly with the horizontal load.

3) Maximal deformation

And the variation of the maximal deformation is shown in Figure 26.

Deformations grow quickly with an inflexion point at the load of $1.2 \times 10^{8}$ $\mathrm{N} / \mathrm{m}^{2}$ and an increase of the increasing velocity after. That inflexion point could represent the failure of vertical chaining of the wall. 


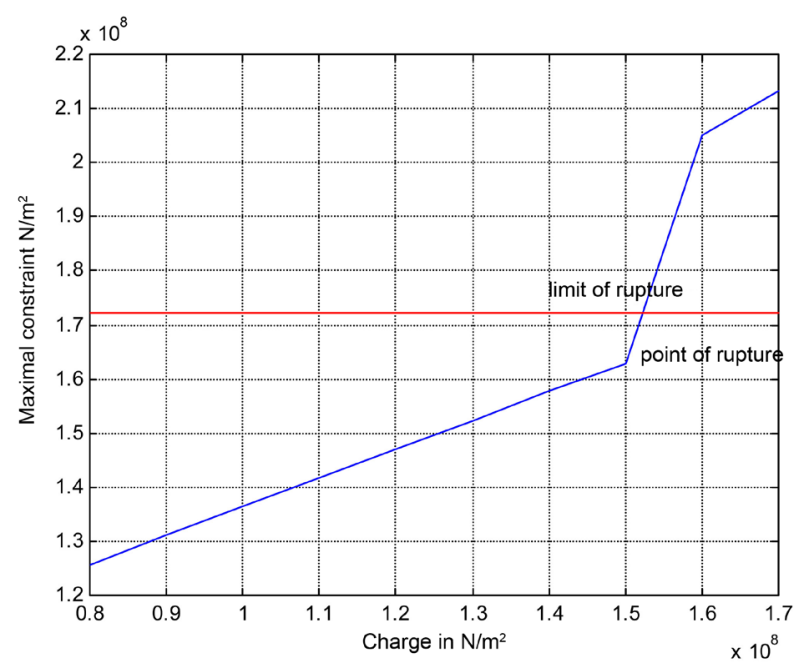

Figure 24. Maximal constraints on the new wall under composed solicitations.

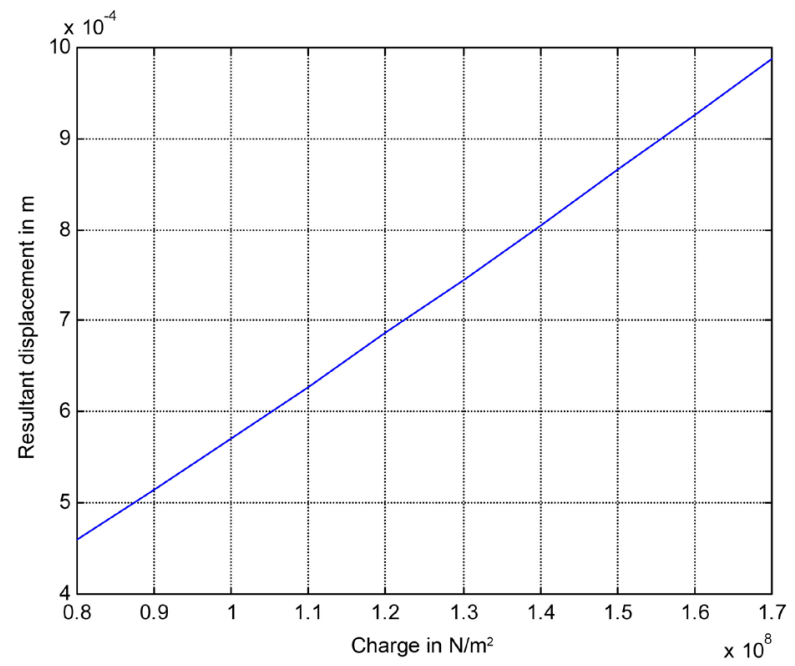

Figure 25. Resultant displacements on the new wall under composed solicitations.

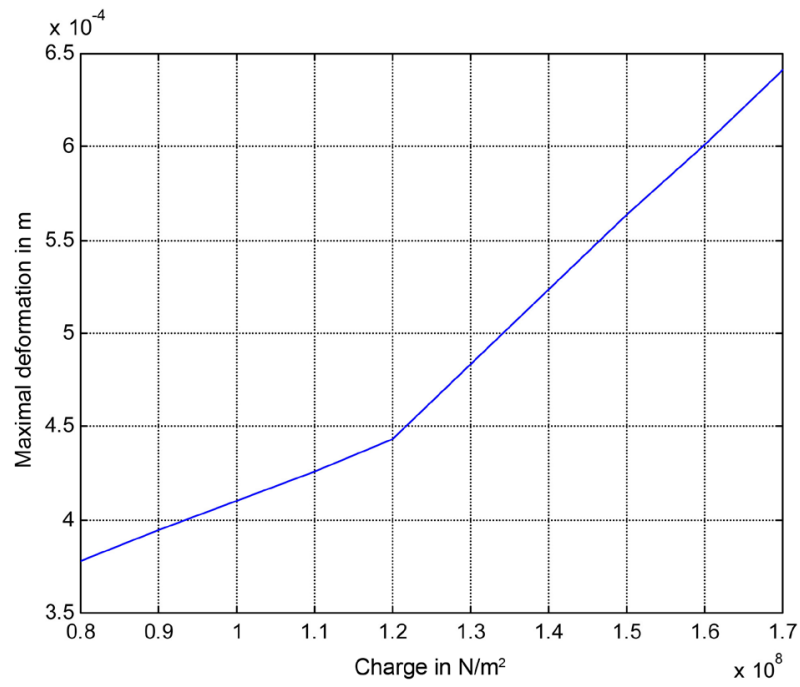

Figure 26. Maximal deformations on new wall under composed solicitations. 


\subsubsection{Simulation of the Behavior of Traditional Wall under Composed Loading}

In the same way, we have also submitted the short walls under normal fix effort of $30 \times 10^{6} \mathrm{~N} / \mathrm{m}^{2}$, and a horizontal variable loading at the head of the wall (Figure 27).

The traditional wall up there submitted at the same conditions than the new wall (Figure 23), then we observe the following results presented in Table 6.

In this case we observed the following behaviors:

1) Maximal constraint

The maximal constraint is represented by Figure 28 .

Figure 28 shows many inflexion points before the limit of failure. We can think that constraints increase as the different points broke. That behavior is different to the one of the traditional wall where the constraints increase regularly until an inflexion point situated at the load $1.5 \times 10^{8} \mathrm{~N} / \mathrm{m}^{2}$, but those constraints still below to those of new wall.

\section{2) Maximal displacement}

The maximal displacement in this case is represented by Figure 29.

Here, displacements increase quickly and regularly with the values over to those obtained for the new wall.

3) Maximal deformation

When submitted to compose solicitations, the maximal deformations of traditional wall are as follow (Figure 30).

Deformations have many variations of the increasing velocity before taking a fast increasing from the load $1.2 \times 10^{8} \mathrm{~N} / \mathrm{m}^{2}$ with values sensibly equal to those obtained on the new wall. We note that the main inflexion point (load $1.2 \times 10^{8}$ $\mathrm{N} / \mathrm{m}^{2}$ ) is the same for the two models of masonries.

That work could go on by simulations and trials with the same short walls under seismic loads.

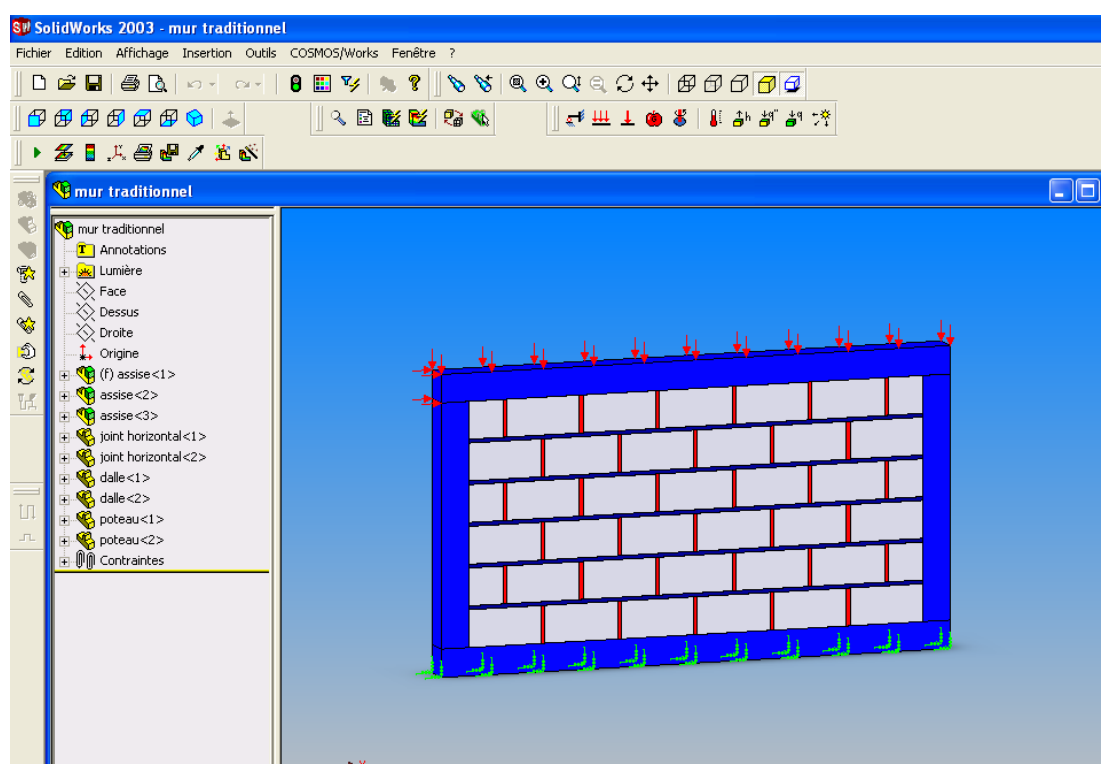

Figure 27. Traditional wall under composed loading. 


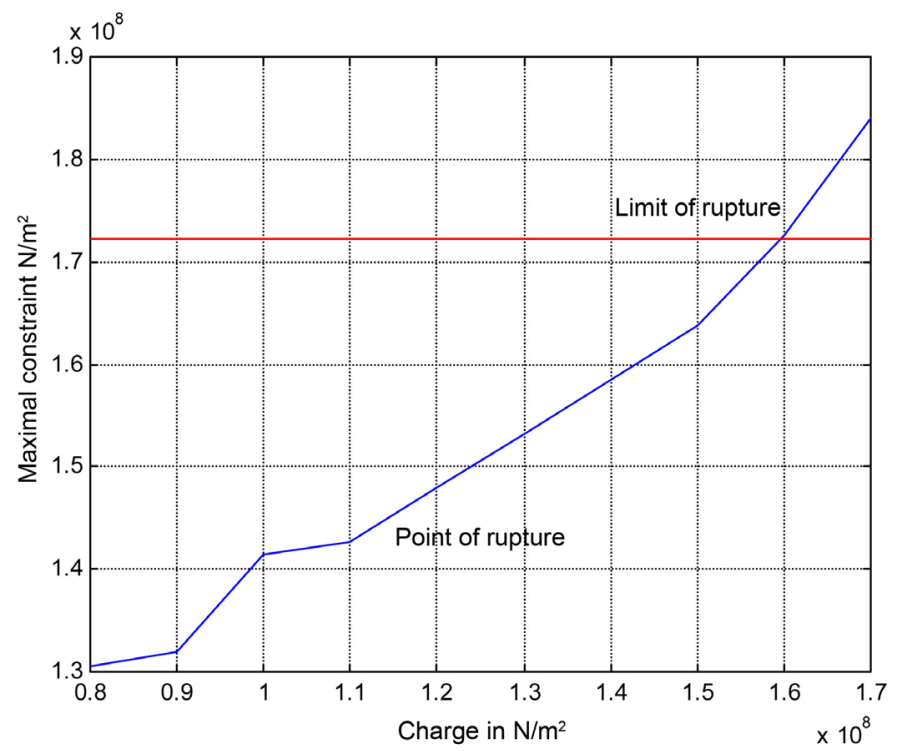

Figure 28. Maximal constraints on traditional wall under composed solicitations.

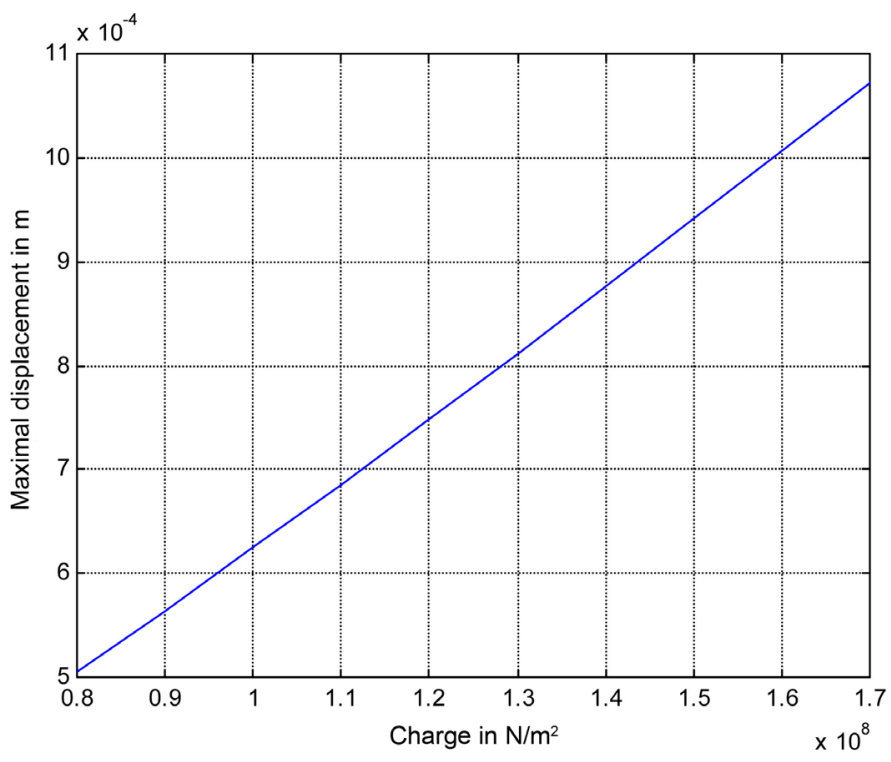

Figure 29. Resultant displacement on traditional wall under composed solicitations.

Table 6. Results of simulations on a traditional wall under composed loading.

$\begin{gathered}\text { Normal } \\ \text { effort } \times 10^{6} \mathrm{~N} / \mathrm{m}^{2}\end{gathered}$
$\begin{gathered}\text { Tangential } \\ \text { effort } \times 10^{5} \mathrm{~N} / \mathrm{m}^{2}\end{gathered}$




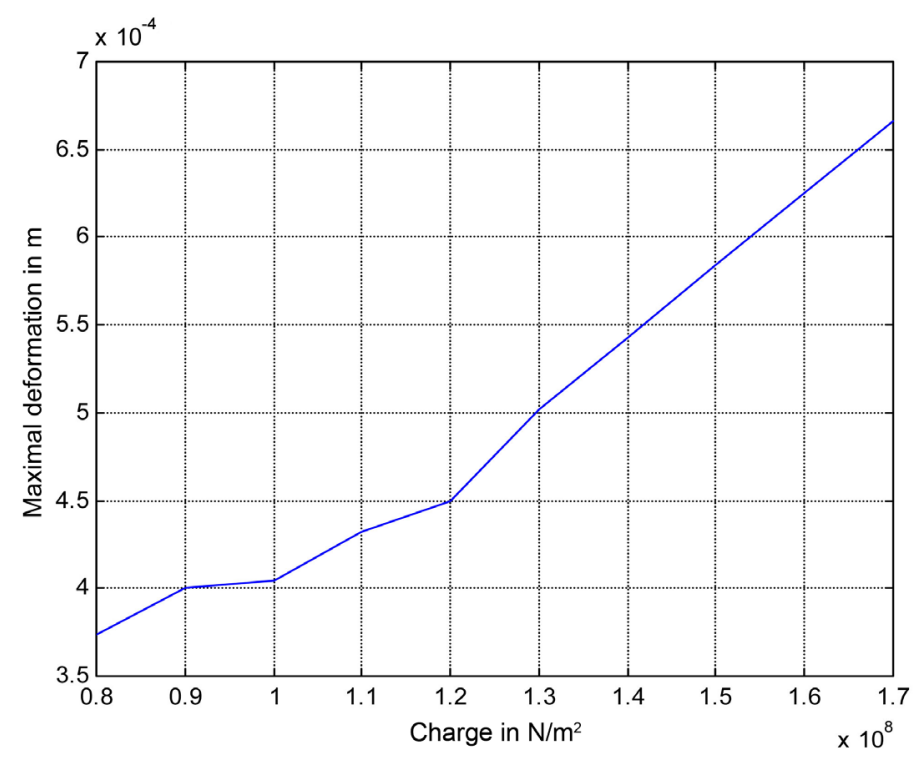

Figure 30. Maximal deformations on traditional wall under composed loading.

\subsubsection{Conclusion on Those Simulations}

Those simulations on the two types of masonries have allow us to conclude that when submitted at normal effort only, or at composed loading, the new model of masonries whenever developing the most important constraints than the traditional model, have less displacements and deformations. This is explained by the presence of vertical dry joints which constitute areas of dissipating energy of deformation. That notice leads us to conclude the failure for traditional masonries occurs more early than the one for new masonries, and then, the new model has at less the same performance than the traditional.

More, the repartition of constraints, displacements and deformations seems to follow diagonals for the case of traditional walls, when in the same time; it allows to observe concentration of big values on odd seats for the new walls. That allows to confirm that small elements (considering dimensions) always carry better than the greats (even seats), and to affirm that if failure, traditional masonries show cracks from up to down following diagonals, meanwhile the new masonries have more isolated cracks; that allows them to have a more important residual resistance at failure.

\section{General Conclusion and Perspectives}

The main objective of that study was to simulate for different conditions of loading, traditional masonries and those with eviscerated bed joints and hollow vertical joints. For that purpose, we use finite elements method implemented by COSMOS and MATLAB. Solidworks helped us to design the walls with all necessaries constraints. We globally noted that the design of the new masonries is not a handicap for its mechanical behavior; but, in the conditions of vertical load and horizontal punctual load applied on one chipboard, those walls are poor: this is mainly because of hollow vertical joints. 
The essential mechanical characteristics of walls present a variability which is important to take into account in the sizing. For that purpose, it would be interesting to make a probability study considering the angle of inclination of connecting rods variables determinist, and the resistances in horizontal and vertical compression of blocks as random variables.

Mechanic characteristics of materials which constitute walls show an intrinsic variability that need to be taken in consideration in design. At that effect, it may be interesting to do a probabilist study considering the geometry and the inclination angle of connecting nod as determinist values, horizontal and vertical resistances of blocks as aleatory values. We can imagine that it exists between those two sizes a big correlation, because blocks always show the same intern geometry, conditioned by the one of moulds used. This allows to consider only one aleatory variable. Finally, in order to deny that this variable takes negative values, we could suppose that it follows a log-normal distribution law (near to the ideal which is normal law). That is an axis to explore.

Our study may also be ameliorated in the future through simulations with trials on dynamics charges, on one part, and on the other part, by trials on a bench in laboratory which is already available. This may permit to give global recommendations for the use of the new masonries.

\section{Conflicts of Interest}

The authors declare no conflicts of interest regarding the publication of this paper.

\section{References}

[1] INS (2001) Pauvreté, habitat et cadre de vie au Cameroun en 2001. Deuxièmeenquête Camerounaiseauprès des ménages, ECAM II.

[2] Adjovi, E., Ayina, O. and Bikoun, J. (2010) Conception and Estimation of Total Dry Cost Based on Matrix Calculation. Laboratoired' Energétique et Mécanique Appliquée (LEMA)-Béninet Laboratoire de Mécanique, Matériaux, Structures et Productique $\left(\mathrm{LM}^{2} \mathrm{SP}\right)$, Douala.

[3] Houngbo, G. and Karimou, S. (2005) Contribution à la réduction du coût du gros-œuvre et à la protection de l'environnementcôtier: Utilisation du sable lagunaire et de blocs spéciauxdans la réalisation des maçonneriesenaggloméréscreux de 15 cmd'épaisseur. Mémoire de fin d'étudessoutenu à l'Ecolepolytechniqued' Abomey-Calavi, département de génie civil. Benin.

[4] Bikoun, J. (2006) Modélisationnumérique du comportementmécanique des maçonneriesenagglomérésautobloquants à joints verticaux secs et joints horizontauxévidés. mémoire de DEA, Université de Douala.

[5] Cruz Diaz, J., Sellier, A., Capra, B., Delmotte, P., Rivillon, P. and Mebarki, A. (2002) Resistance of Masonry Infill Walls to Racking Loading: Simplified Model and Experimental Validation. Masonry International, 15, 59-86.

[6] Delmotte, P., Rivillon, P., Wesierski, V. and Hurez, M. (2003) Etudes des murs de contreventementenmaçonnerie de blocs creuxenbéton. Cahiers du CSTB, livraison 445 , cahier 3491 . 
[7] Bikoun, J. (2006) Modélisationnumérique du comportementmécanique des maçonneriesenagglomérésautobloquants à joints verticaux secs et joints horizontauxévidés. mémoire de DEA, Université de Douala.

[8] Colliat, J.-B., Davenne, L. and Ibrahimbegovic, A. (2002) Modélisationjusqu'à rupture des mursenmaçonnerie chargés dansleur plan. Revue Française de Génie Civil, 6, 593-606. https://doi.org/10.1080/12795119.2002.9692390

[9] Zienkiewicz, D.C. (1990) The Finite Element Method. 4th Edition, McGraw Hill, Boston.

[10] Perales, R. (2007) Modélisation du comportementmécanique par élémentsdiscrets des ouvragesmaçonnéstridimensionnels. Contribution à la définition d'éléments de contacts surfaciques. Thèsedoctorat, Université Montpellier II.

[11] Pande, G.N., Liang, J.X. and Middleton, J. (1990) Equivalent Elastic Modulo for Brick Masonry. Computers and Geotechnics, 8, 243-265. https://doi.org/10.1016/0266-352X(89)90045-1

[12] Papa, E. and Nappi, A. (1993) A Numerical Approach for the Analysis of Masonry Structures. Masonry International, 7, No. 1.

[13] Chopra, A.K. and Chintanapakdee, C. (2003) Inelastic Deformation Ratios for Design and Evaluation of Structures: Single Degree of Freedom Bilinear Systems. Pacific Earthquake Engineering Research Center, University of California, Berkeley, Report 2003-09, 81 p.

[14] Cruz Diaz, J., Sellier, A., Capra, B., Delmotte, P., Rivillon, P. and Mebarki, A. (2001) Modélisationsimplifiée du comportement à rupture des murs. Revue Française de Génie Civil, 5, 613-627. https://doi.org/10.1080/12795119.2001.9692714

[15] Bui, T.T. (2013) Etude expérimentale et numérique du comportement des voiles enmaçonneriesoumis à un chargement hors plan. Thèsedoctorat, Institut National des Sciences Appliquées de Lyon, France.

[16] Dhanasekar, M., Page, A.W. and Kleenan, P.W. (1985) The Failure of Brick Masonry under Biaxial Stresses. Proceedings of the Institution of Civil Engineers, 79, 295-313. https://doi.org/10.1680/iicep.1985.992

[17] Lourenço, P.B., Oliveira, D.V., Roca, P. and Orduna, A. (2005) Dry Joint Stone Masonry Subjected to In-Plane Combined Loading. Journal of Structural Engineering, 131, 1665-1673. https://doi.org/10.1061/(ASCE)0733-9445(2005)131:11(1665) 